\title{
Editorial / Editoriale
}

\section{Indices and COPD Gli indici e la BPCO}

\author{
Peter Howard \\ Former Head of University Department of Respiratory Medicine, Royal Hallamshire \\ Hospital, Sheffield, UK
}

The paper by Inal-Ince and colleagues (pag. 162-167) examines fatigue in chronic obstructive pulmonary disease (COPD) relating it to multi dimensional indices of overall disease severity, BODE and SAFE. It is the selection of these indices that will be examined in this Editorial.

COPD is now considered a multi dimensional disease, in fact, quite remarkably so. A little history will remind how this situation has arisen.

Fifty to 60 years ago in post War years, the terms chronic bronchitis and emphysema were used to define the emerging airway disorders associated with smoking, occupation and air pollution. Chronic bronchitis was defined by sputum production, emphysema by hyperinflated lungs and breathlessness. Both conditions were associated with airways obstruction measured by the early spirometers.

Bronchitics tended to be less short of breath but develop early oedematous respiratory failure. Patients with emphysema were more obviously breathless, emaciated and developed respiratory failure late. The term 'blue bloater' was coined for the first group, and 'pink puffer' for the second group. In the chest clinics of Europe, the 'blue bloater' configuration was very common, filling hospital wards in winter months. It was never possible to isolate these groups into distinct clinical entities despite their obvious differences; rather, they proved to be polar ends of a disease spectrum in which most patients were clustered in the middle with features of both.

The terms were eventually dropped and the generic term of COPD introduced. The clinical features were daily sputum (now much less), shortness of breath, exacerbations and eventual death in respiratory failure. It was a progressive disease, with a variable speed of decline, in some cases remarkably swift, but for most the course was indolent.
COPD encompassed all forms of the disease. It was recognised as heterogenous. The next 20 to 30 years to the present day have been spent defining the clinical, physiological and pathological components. COPD has emerged as a systemic disease centred on the lungs. A new term has been coined labelling COPD as a 'multi dimensional' disease.

The clinician is concerned with airways obstruction, shortness of breath, exacerbations and respiratory failure. All patients have a degree of debility expressed as loss of appetite, fatigue and neuropsychological impairment. Some patients exhibit marked loss of weight and poor peripheral muscle endurance.

The clinician uses simple monitoring tools - chest $\mathrm{x}$-ray, spirometry to measure $\mathrm{FEV}_{1}, \mathrm{FVC}$ and reversibility to bronchodilators, 6 minute walking test (6MWT) - sometimes a shuttle test incorporating breathlessness scales to achieve a percentage of disability and arterial blood gases. Occasional lung volumes and transfer factor assist with physiological evaluation. Some hospital departments use questionnaires occasionally such as the St George's Respiratory questionnaire (SGRQ) to obtain a holistic measure of the impact of the disease on quality of life.

These tests are used to monitor deterioration of the disease and response to pharmacological treatments, rehabilitation, treatment of exacerbations etc. They have done well, all are now standardised, reproducible and simple to administer. Respiratory function laboratories, an important part of chest disease departments, carry out the tests.

Physiologists and researchers use many other tests to examine the basic mechanisms of disease such as inflammation, oxidative stress, physiological disturbances such as mechanisms of breathlessness, hypoxia, depression of ventilatory drive, exercise impairment and so on. These tests are not mainstream

\footnotetext{
$\Xi$ Peter Howard

Former Head of University Department of Respiratory Medicine, Royal Hallamshire Hospital

3 Sandygate Park, Sheffield S10 5Z, UK

email: dr.howard@btconnect.com
}

Multidisciplinary Respiratory Medicine 2010; 5(3): 160-161 
to the treating physician in normal circumstances. The multi dimensional nature of COPD is now attracting multi dimensional indices to assess it. These

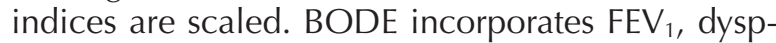
nea scales, exercise capacity (6MWT) and nutritional state (body mass index) [1]. SAFE uses a standardised health related quality of life assessment tool, SGRQ in addition to $6 \mathrm{MWT}$ and $\mathrm{FEV}_{1}(2)$. Are these indices better clinical indicators of disease progression and response to treatment than the single pa- rameters in use for so long?

Inal-Ince and colleagues found the BODE and SAFE indices related to impaired peripheral muscle endurance and fatigue perception, but then so were $\mathrm{FEV}_{1}$ alone and the GOLD classification of overall disease severity. BODE scores in other studies correlate with exacerbations and survival [1-3].

What really needs to be known is whether these indices are of value to the clinician over and above the simple tests established for so many years.

\section{References}

1. Celli BR, Cote CG, Marin JM, Casanova C, Montes de Oca M, Mendez RA, Pinto Plata V, Cabral HJ. The body-mass index, airflow obstruction, dyspnea, and exercise capacity index in chronic obstructive pulmonary disease. $N$ Eng J Med 2004;350:1005-1012.

2. Azarisman MS, Fauzi MA, Faizal MP, Azami Z, Roslina AM, Roslan $\mathrm{H}$. The SAFE (SGRQ score, air-flow limitation and 